\section{An Analysis of the Beta-Attenuation Technique for Estimating Standing Crop of Prairie Range ${ }^{1}$}

\section{J. E. MITCHELL}

Department of Range Science and Natural Resource Ecology Laboratory, Colorado State University, Fort Collins.

\section{Highlight}

The standing crop of aboveground shortgrass prairie vegetation may be quickly and accurately estimated by the beta-attenuation technique. This technique is based upon the principle that herbage absorbs or attenuates beta particles emitted by certain radioactive nuclides as a predictable function of the herbage biomass intersecting the attenuation field between emitter and detector. Two

1 This papcr reports on work supportcd in part by National Science Foundation Grant GB-13096 for Analysis of Structure and Function of Grassland Ecosystems. Received August 23, 1971. methods of measurement are correlated with standing vegetation. These tests indicate that the method can account for approximately $90 \%$ of the variation measured in the field, with the exception of quadrats dominated by plains prickly pear. In addition to being accurate, precise, and relatively inexpensive, the beta-attenuation technique is nondestructive in nature, allowing repetitive sampling of the same location.

Range ecologists and others involved in studies of the structure and function of rangeland ecosystems, or their inventory for management purposes, have continually attempted to improve upon existing procedures for estimating herbage biomass accurately, precisely, quickly, and inexpensively. The methods most commonly utilized in range research involve clipping to at least some degree. However, there are one or two characteristics of clipping which tend to limit its usefulness. First, clipping tends to be slow, arduous, and costly to utilize. Secondly, clipping is a destructive sampling procedure, precluding a quadrat from being sampled repetitively.

The most commonly used method for estimating herbage biomass nondestructively is the ocular 


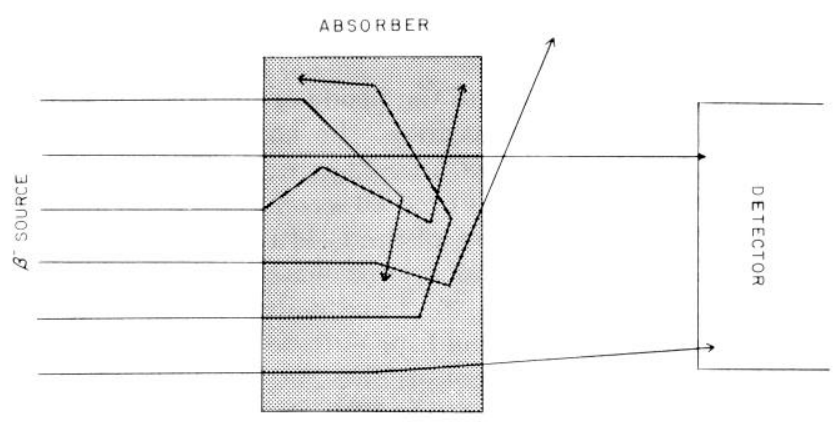

FIG. 1. Schematic diagram of beta-particle attenuation. Standing crop of quadrat vegetation is portrayed by the absorber box.

estimation procedure (Pechanec and Pickford, 1937). For purposes of general range inventory the ocular estimation method is satisfactory. On the other hand, for some kinds of research and more specialized range resource inventory, more accurate techniques are required.

The first piece of equipment for directly measuring herbage biomass was constructed by Fletcher and Robinson (1956). Their capacitance meter was based on the principle that air has a low dielectric constant while herbage has a high dielectric constant. Unfortunately, water with a dielectric constant of about 80 has much more influence than dry forage with a constant of about 5 (Weast, 1969), causing variations in both plant and soil moisture to bias capacitance readings significantly on occasion. There has been significant progress in improving upon the original capacitance meter, however, and many of such studies are still ongoing (Van Dyne et al., 1968).

The first use of radioisotopes to determine herbaceous biomass was reported by Teare et al. (1966). According to the authors this technique, termed beta-attenuation, relies on the "thickness gauging" principle where the absorption or attenuation of beams of radioactive emissions (beta-particles) is a predictable function of the density of absorbing material (herbage) in $\mathrm{mg} \mathrm{cm}^{-2}$. Herbage density data may be transformed directly to biomass information if it is integrated over plant height, thereby allowing standing crop to be the dependent variable in a regression against radioactivity. Working with such agronomic crops as wheat and soybeans, Teare and his colleagues reported that their "betafoliagometer" allowed them to produce linear regression equations accounting for $98 \%$ of the variation in wet weight standing crop.

\section{Equipment}

The equipment necessary for an analysis of herbaceous biomass by beta-attenuation must include both a radioactive source and some kind of detector/recorder. A schematic diagram of the system is shown in Fig. 1.

There are several feasible radioactive sources which may be utilized for studies of this type. Table 1 lists several of those which are available for use by qualified users. The
Table 1. List of radioisotopes which may be utilized for "thickness gauging" by beta-attenuation.

\begin{tabular}{lcc}
\hline \hline \multicolumn{1}{c}{ Isotope } & Energy & Half-life \\
\hline Carbon $^{14}$ & $.16 \mathrm{Mev}$ & $5.7 \times 10^{3}$ years \\
Chlorine $^{36}$ & .71 & $3.0 \times 10^{5}$ \\
Krypton $^{85}$ & .67 & 10.4 \\
Strontium $^{90}$ & 2.27 & 28.0 \\
Thallium $^{204}$ & .77 & 3.9 \\
\hline
\end{tabular}

choice of source will depend upon the density of vegetation to be sampled. For example, strontium ${ }^{90}$, chlorine ${ }^{36}$, and carbon $^{14}$ may be utilized for 600,200 , and $25 \mathrm{mg} \mathrm{cm}^{-2}$ maximum density respectively (Teare et al., 1966). In addition to the energy requirements, a source should also have a long half-life and be economically available to the user.

A Geiger-Mueller (G-M) tube is commonly used to detect beta emissions. For the softer betas, a thin-windowed G-M tube is necessary, requiring cautious use in the field to keep it from being punctured. The term "soft beta" may be used to qualitatively define those beta-emitters with a maximum energy below about $0.5 \mathrm{MEV}$. There are two types of recording apparatus which may be connected to a G-M tube: (1) a ratemeter such as incorporated into a survey meter, or (2) a portable scaler which gives a more precise digital readout in counts per minute.

For the implementation of this experiment, 10 microcuries $(\mu \mathrm{Ci})$ of strontium ${ }^{90}$ were acquired on loan from the Radiology and Radiation Biology Department at Colorado State University, Fort Collins. The isotope, in liquid form, was applied uniformly over the entire area of an $8 \times 10$-inch sheet of paper marked off into square centimeters. When the radioactive solution had dried, the sheet of paper was sealed inside an acetate document protector (Fig. 2).

The detector/scaler equipment was also made available during the experimental period by the CSU Radiology and Radiation Biology Department. This consisted of a Ludlum Model 20-A portable, battery-powered scaler and a Ludlum Model 44-7 Geiger-Mueller tube with an end window (Fig. 2). Since the G-M tube had a thin window, a plastic bag was placed over it for protection.

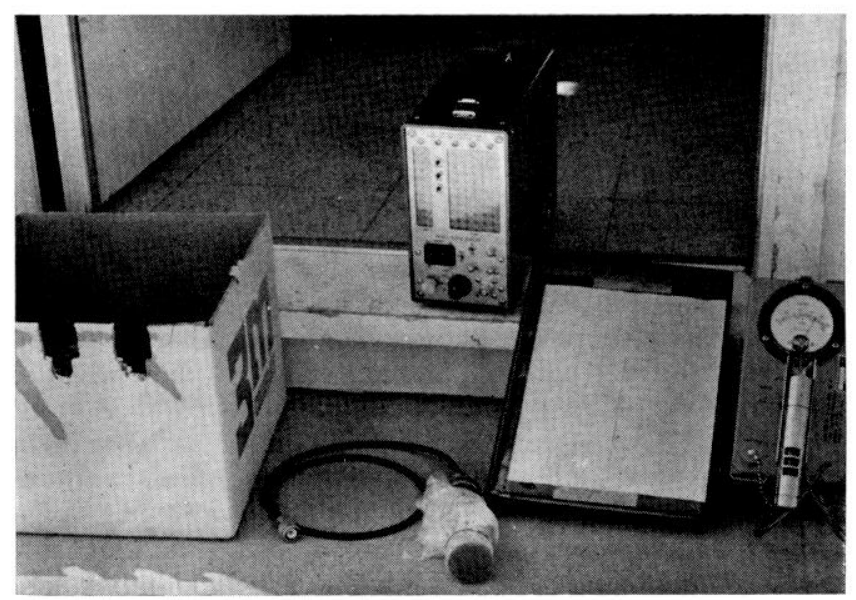

FIG. 2. Equipment necessary for herbage biomass estimation by beta-attenuation. From left are: notched box, Geiger-Mueller tube (with protective plastic bag), portable scaler, radioactive source, and a survey meter. 


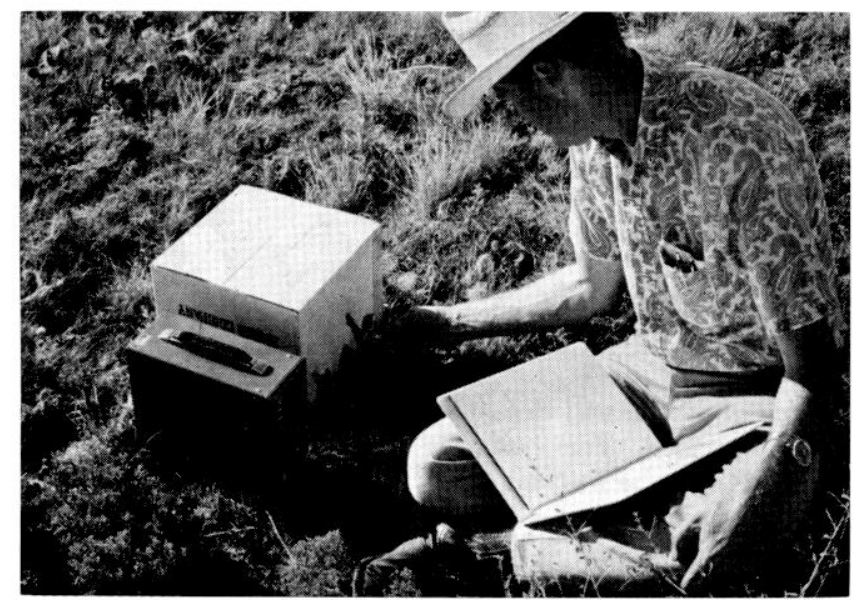

Fig. 3. A view showing the relative positions of the G-M tube and the box which holds the beta-emitting source.

\section{Experimental Area and Methods}

The data collection was carried out during latter June and early July 1970 at the International Biological Program (IBP) Grasslands Biome Pawnee Site, which is located on the Central Plains Experimental Range about 30 miles northeast of Fort Collins, Colorado. This area is a shortgrass plains dominated by blue grama (Bouteloua gracilis (H.B.K.) Lag.) and buffalo grass (Buchloe dactyloides (Nutt.) Engelm.). Mean precipitation is about 12 inches per year, most of which occurs in the spring, summer, and early fall. A more complete site description has been given by Klipple and Costello (1960).

The pasture from which the samples were taken had been excluded from cattle grazing since the previous year. There was, however, evidence of light grazing by small mammals and phytophagus insects. This utilization tended to be nonuniform, apparently due to the presence of plains prickly pear (Opuntia polyacantha Haw.) which precluded the harvest of forage from areas up to $2 \mathrm{~m}$ in diameter.

Forty-five random samples were collected during the last week in June and the first two weeks in July of 1970. The procedure followed during any given sampling period was as follows: The $8 \times 10$-inch acetate sheet containing the strontium ${ }^{90}$ source was taped to an interior side of an opentopped cardboard box dimensioned 10.1 inches long $\times 10.1$ inches wide $\times 9$ inches high. Along the top edge of the box opposite to the side to which the source was taped, three equidistantly-spaced, circular notches were cut out (Fig. 2). These notches served as portholes for the end-windowed G-M tube during the sampling process. The data were collected by turning the box upside down and placing it over the quadrat to be sampled. The cardboard box thereby served four functions: (1) it held the source sheet perpendicular to the ground and out of the wind; (2) since it was inverted for use, the box's bottom helped to compress the taller forbs and grasses such as slimflower scurfpea (Psoralea tenuiflora Pursh) and red threeawn (Aristida longiseta Steud.) down into the attenuation field; (3) it defined the plot size. Although the box covered slightly more than $1 / 16$ th square meter, all biomass data were subsequently corrected to a square-meter basis in the analyses. (4) Finally, the notched box was used to assure that the G-M tube was kept in the same relative position to the source for each sample, thereby assuring that the geometry of the attenuation field remained constant.

After taping the source to the inside of the box and having determined a sampling location, the box would be placed inverted over the plot and four 12-penny nails pushed into the soil at each corner. Three 60-second counts were then taken with the end window of the G-M tube even with each of the pre-cut notches and approximately one fourth inch above the soil surface (Fig. 3). Finally, the box was removed, heavy twine run around the four nails to redefine the quadrat, and the plot clipped of all live and dead aboveground vegetation. The clipped material was later oven-dried at $55 \mathrm{C}$. Both wet weights (i.e., field weight immediately after clipping) and oven-dry weights were recorded. In addition to the biomass data, the dominant species occurring on the quadrat were also noted.

When the beta source was not being used in the field, safety regulations required that it be secured in a locked cabinet marked with the standard U.S.A.E.C. warning symbol for radioactivity. About three to four hours were required to take ten samples, including selection of the quadrat location, counting, clipping, determining the wet herbage weight, returning to the on-site laboratory (1 mile), placing the samples in an oven, and weighing the oven-dried samples. An insignificantly small amount of this time was taken up in the counting phase, which is all that would normally be required if the technique were an established method and already calibrated for the particular site.

\section{Results}

Eight regression models, with herbage biomass comprising the dependent variable and beta activity in counts per minute the independent variable, were postulated for analysis with the data collected. According to Teare et al. (1966) the activity or attenuated count rate is exponentially related to absorber thickness; therefore, one-half of the models tested the null hypothesis after activity rates had been transformed by taking their natural logarithm. The effect of taking three counts vs. taking one count (middle notch considered only) per sample was also tested, with the reasoning that the mean of three readings would give a more integrated measure of the true density of obviously nonuniform quadrats. Each of the above count-rate information sets were correlated to both wet and oven-dry forage weights, thereby giving eight regression models in all.

Preliminary analyses consistently were insignificant with coefficients of determination below 0.6 . Much of the error was due to data from plots dominated by plains prickly pear. Consequently, all quadrats dominated by plains prickly pear were omitted from the analyses, leaving a sample size of 35. With the reduced sample, coefficients of determination ranged from 0.90 to 0.94 .

The summary statistics for each model are shown in Tables 2 and 3 . In addition, a graphical representation of the general regression model, using Table 2-A as an example, is depicted in Fig. 4. As was expected, both the three-count combination 
Table 2. Results of four regression equations predicting herbage standing crop ( $Y$ ) on a wet-weight basis from attenuated beta radioactivity rates $(X)$ on a shortgrass prairie. $\mathbf{X}_{2}$ is defined as the activity rate at the middle notch.

\begin{tabular}{|c|c|c|c|c|}
\hline \multicolumn{4}{|c|}{ A. $Y=296.7-.040 X_{2}$} & $\mathrm{r}^{2}=.916$ \\
\hline & S.S. & $\mathrm{df}$ & M.S. & $\mathbf{F}$ \\
\hline Regression & 60055.5 & 1 & 60055.5 & 360.4 \\
\hline Error & 5499.6 & 33 & 166.6 & \\
\hline Total & 65555.1 & 34 & & \\
\hline \multicolumn{4}{|c|}{ B. $\mathrm{Y}=300.9-.044\left(\mathrm{X}_{1}+\mathrm{X}_{2}+\mathrm{X}_{3}\right) .333$} & $\mathrm{r}^{2}=.932$ \\
\hline & S.S. & $\mathrm{df}$ & M.S. & $\mathbf{F}$ \\
\hline Regression & 61082.5 & 1 & 61082.5 & 450.7 \\
\hline Error & 4472.6 & 33 & 135.5 & \\
\hline Total & 65555.1 & 34 & & \\
\hline \multicolumn{4}{|c|}{ C. $\mathrm{Y}=1769.6-197.18\left(\ln \mathrm{X}_{2}\right)$} & $\mathrm{r}^{2}=.916$ \\
\hline & S.S. & df & M.S. & $\mathbf{F}$ \\
\hline Regression & 60061.6 & 1 & 60061.6 & 360.8 \\
\hline Error & 5493.5 & 33 & 166.5 & \\
\hline Total & 65555.1 & 34 & & \\
\hline \multicolumn{4}{|c|}{ D. $Y=1811.3-203.66\left(\ln \left(\mathrm{X}_{1}+\mathrm{X}_{2}+\mathrm{X}_{3}\right) .333\right)$} & $\mathrm{r}^{2}=.940$ \\
\hline & S.S. & df & M.S. & $\mathbf{F}$ \\
\hline Regression & 61619.6 & 1 & 61619.6 & 516.7 \\
\hline Error & 3935.5 & 33 & 119.3 & \\
\hline Total & 65555.1 & 34 & & \\
\hline
\end{tabular}

and the logarithmic transformation added slightly to the significance of the regression. In all cases the attenuated beta activity was a slightly better predictor of herbage wet weight than dry weight.

Table 3. Results of four regression equations predicting herbage standing crop $(Y)$ on an oven-dry basis from attenuated beta radioactivity rates $(X)$ on a shortgrass prairie. $X_{2}$ is defined as the activity rate at the middle notch.

A. $\mathrm{Y}=208.2-.028 \mathrm{X}_{2}$ S.S.

Regression $\quad 29442.8$

Error

Total

3221.0

32663.8

B. $\mathrm{Y}=210.6-.031\left(\mathrm{X}_{1}+\mathrm{X}_{2}+\mathrm{X}_{3}\right) .333$

$\begin{array}{lrr} & \text { S.S. } & \mathrm{d} \\ \text { Regression } & 29750.8 & 1 \\ \text { Error } & 2913.0 & 33 \\ \text { Total } & 32663.8 & 34\end{array}$

C. $\mathrm{Y}=1242.6-138.43\left(\ln \mathrm{X}_{2}\right)$

\begin{tabular}{lrr} 
& \multicolumn{1}{c}{ S.S. } & df \\
Regression & 29603.6 & 1 \\
Error & 3060.2 & 33 \\
Total & 32663.8 & 34
\end{tabular}

D. $\mathrm{Y}=1267.6-142.47\left(\ln \left(\mathrm{X}_{1}+\mathrm{X}_{2}+\mathrm{X}_{3}\right) .333\right)$

$\begin{array}{lcccc} & \text { S.S. } & \text { df } & \text { M.S. } & \text { F } \\ \text { Regression } & 30153.0 & 1 & 30153.0 & 396.3 \\ \text { Error } & 2510.8 & 33 & 76.1 & \\ \text { Total } & 32663.8 & 34 & & \end{array}$

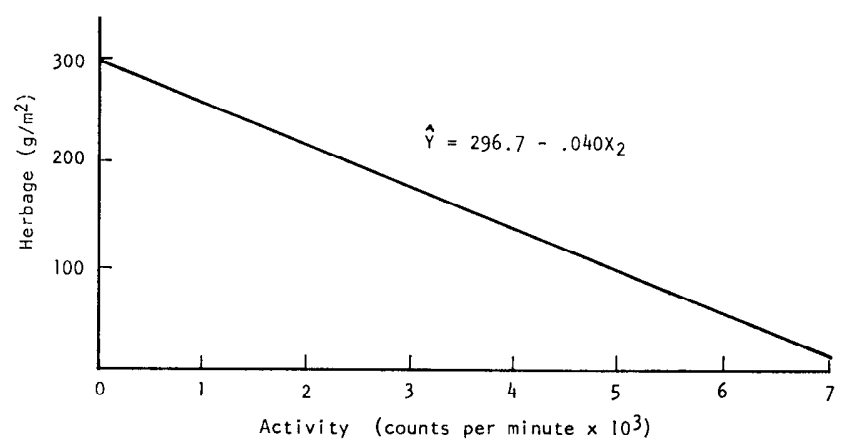

FIG. 4. Relationship between beta activity and herbage biomass (wet weight) using only one count per sample.

The real significance of the statistics, in the author's opinion, lies not in the comparisons among different models, but rather in the high predictability of each of thesc rcgrcssions in determining herbage biomass with such a low cost and relatively unsophisticated first-pass experiment.

\section{Discussion and Conclusions}

When the data variables were plotted against each other it was apparent that the greatest variation was at the high end of the $\mathrm{X}$-axis, i.e., high count rate and low biomass. Thus, it is doubtful that the beta-attenuation technique would have been useful on a moderate to heavy grazed shortgrass prairie. However, such a situation is a worstpossible case.

The roughness of the soil surface also contributed to the magnitude of the error term. It is not difficult to imagine the effect of microtopography, such as a small hill protruding into the attenuation field or herbage growing in the protection of a slight depression, on the goodness of fit. Such an effect is compounded on a shortgrass prairie where the microtopographical variation can be as great or greater than the vegetation.

A potential second source of error must be considered whenever radioactivity rates are being measured. All radioactive emissions are random, nonuniformly occurring events, and any instantaneous or momentary measurement of them may only be described in terms of statistical parameters. The usual manner for circumventing this source of error is to record cumulative activity over a reasonable length of time, which is why 60 -second counts were used as described above.

There are procedures and restrictions pertaining to the safe handling of radiosotopes which are prescribed by the Atomic Energy Commission and, in many cases, related state agencies. For example, there is a maximum users amount, called a control unit and defined in microcuries, set for each isotope. As long as the material needed is less than one control unit, these regulations will allow any competent biologist to utilize that particular radio- 
isotope with a minimum of labeling requirements, waste disposal restrictions, etc. There should be no reason to require more than this amount in setting up the beta attenuation technique for the measurement of primary production on any rangeland ecosystem. It must be emphasized, however, that scientists and range managers interested in this technique who are not experienced in the handling of radioisotopes should consult with an appropriate organization or agency before making any plans on their own, no matter how minute the quantity of isotope which is to be used.

The beta-attenuation procedure is one which has been largely overlooked as a research or management tool in range resource analysis. It may especially be uscful in double sampling as the extensive or inexpensive component of the method. Although the requirement for frequency of calibration was not tested, it seems likely that calibration may be much less of a problem than with the capacitance meter.

\section{Literature Cited}

Choppin, G. R. 1964. Nuclei and radioactivity. W. A. Benjamin, Inc., New York. $150 \mathrm{p}$.

Fletciler, J. E., AND M. E. Robinson. 1956. $\Lambda$ capacitance meter for estimating forage weight. J. Range Manage. 9: 96-97.

KlipPle, G. E., AND D. F. Costello. 1960. Vegetation and cattle responses to differcnt intensitics of grazing on shortgrass ranges of the central Great Plains. U.S. Dep. Agr. Tech. Bull. 1216. 82 p.

Pechanec, J. F., and G. D. Pickford. 1937. A weight estimation method for the determination of range or pasturc production. Amer. Soc. Agron. J. 29:894-904.

Teare, I. D., G. O. Mott, And J. R. Eaton. 1966. Betaattenuation-a technique for estimating forage yield in situ. Radiat. Bot. 6:7-11.

Van Dyne, G. M., F. M. Gr.ass, and P. A. Opstrup. 1968. Development and use of capacitance meters to measure standing crop of herbaceous vegetation. ORNL-TM 2247. Oak Ridge Nat. Lab., Oak Ridge, Tenn. 47 p.

WeAst, R. C. [ed.]. 1969. Handbook of chemistry and physics. 50th ed. The Chemical Rubber Co., Cleveland, Ohio. 